Dawson A, Kililo M, Geita L, Mola G, Brodie PM, Rumsey M, Copeland F, Neill A, Homer CSE. Midwifery Capacity Building in Papua New Guinea: Key achievements and ways forward. Women and Birth (accepted 14 October 2015).

\title{
Midwifery Capacity Building in Papua New Guinea: Key achievements and ways forward
}

Background: Papua New Guinea has some of the poorest health outcomes in the AsiaPacific region. Maternal mortality is unacceptably high and there is a severe midwifery shortage requiring a quadrupling of the workforce.

Aim: This paper outlines the findings of an evaluation of the Maternal Child Health Initiative (MCHI) $(2012-2013)$ to determine key factors contributing to maternal health workforce strengthening.

Method: A descriptive mixed methods study was undertaken. Data were gathered through interviews, focus group discussions and surveys with clinicians, midwifery students and staff from nursing and midwifery schools and National Department of Health staff.

Documentation from stakeholder meetings and regular site reports were reviewed. Each data set was analysed separately and meta-inferences were drawn across all data.

Findings: Learning opportunities were found to have increased for midwifery educators and improvements were described in midwifery educators teaching capacity and student clinical education experience. There was an increase in the number of midwifery graduates and improvements were noted in the working environment and skills of clinical staff. Education challenges were described including the lack of clinical preceptoring and limited continuing education for clinical educators. Participants recommended increasing clinical education hours and extending the length of the midwifery program. Ongoing efforts to accredit the midwifery curricula and regulate midwifery graduates were noted. 
Conclusion: The MCHI has contributed to strengthening the midwifery workforce nationally. However, scaling-up and sustaining these achievements requires leadership and funding commitments from the midwifery schools and government alongside the accreditation of midwifery curricula and regulation of new graduates. 


\section{INTRODUCTION}

Building the capacity of midwives to deliver evidence-based interventions to improve maternal health and provide universal access to reproductive health in low and lowermiddle income countries (LMIC) is the focus of a number of international efforts [1]. The report, Scaling up the capacity of nursing and midwifery services to contribute to the MDGs, emphasises the importance of improving key result areas including education and training, engaging nurses and midwives in decision making, enhancing workplace environments, building leadership and global collaboration particularly twinning with other institutions [1].

Insight into ways to translate "key result areas" into action have been outlined in the Strategic Directions for Strengthening Nursing and Midwifery Services 2011-2015 [2]. Scaling up midwifery education involves more than just increasing production. Students need enough competent teachers and the curriculum must be standardised and accredited to ensure success [3]. Endeavours in this area include efforts to develop clinical programs and staff expertise in Africa and Latin America [4, 5]. Materials have been produced to facilitate the involvement of nurses and midwives in decision making around health service planning, policy development [6] and workforce planning [7]. Other initiatives include the networks to enhance workplace environments such as improving employment conditions and reducing violence in the workplace [8]. Examples such as the South Pacific Chief Nursing and Midwifery Officers Alliance [9] and workshops for midwife leaders [10] have provided opportunities to build leadership skills. Finally, examples of global collaboration reveal efforts to strengthen midwifery capacity in many of these key results areas [11].

Despite a range of efforts to build midwifery capacity, there are few donor-funded initiatives with detailed strategies addressing all key result areas in a co-ordinated manner. Few 
international initiatives involve comprehensive interventions across all levels of capacity building [12].These levels of capacity building include the development of midwives' skills, increasing the availability of midwives, improving midwives' supervision and enhancing maternity services through education and health system change [11]. There are however examples where the building of midwifery capacity alongside investment in the health system and overall country development have resulted in dramatic reduction in maternal mortality [13]. These success stories indicate the need for a comprehensive long term commitment and shed light on when and how international development programs could target key result areas for midwifery capacity building and facilitate positive change at all levels.

This paper reports on the progress of the first phase of an Australian Aid funded midwifery capacity strengthening project in Papua New Guinea (PNG) that addressed a critical need to strengthen midwifery in the country. These capacity building strategies includes improving midwifery teaching tools, skills, staff, structures and systems development. The concept of midwifery capacity building is defined in this paper as an approach to the development of sustainable skills, organisational structures, resources and commitment to health improvement in health and other sectors, to prolong and multiply health gains [14]. Capacity building in this context involves working in partnership, in this case with our Papua New Guinean colleagues, to learn to solve problems together. Capacity building uses a strengths-based approach, harnessing opportunities within the current environment and with the support of others, to assist individuals, groups, organizations and governments to build independent capability to bring about positive change. Capacity building programs should be underpinned by appropriate change theories and evaluation processes that 
document the various approaches taken [15]. This includes documenting how new learning is incorporated in an on-going manner and how feasible, pragmatic methods and measures have been used to ensure accountability [16]. Such documentation, in order to share success and learn from challenges, is the focus of this paper.

The Maternal and Child Health Initiative in Papua New Guinea

Papua New Guinea has some of the poorest health outcomes in the Asia-Pacific region and beyond, with a low human development index ranking of 157 out of 187 countries [17]. The maternal mortality ratio (MMR) is one of the highest in the world; estimated to be at 733 per 100000 live births [18]. Forty percent of the population live in poverty [19], only about $40 \%$ of women access a facility-based supervised birth [18]. Despite an urban drift due to poverty, drought and famine, $85 \%$ live in rural and remote areas [20].

PNG has a critical health workforce shortage. In relation to maternal and child health, the country was identified in the first State of the World's Midwifery Report [21] as having a severe midwifery shortage and needing to at least quadruple the workforce. There is 1 midwife per 1,000 births which is well below the international benchmark of 6 per 1,000 births. The reasons for the significant decline in the midwifery workforce over the past decades are multiple and include limited education programs, poor clinical exposure, weak regulation and the absence of a strong professional identity without a clear mandate to improve outcomes or provide leadership for change. In recognition of this extreme situation, the Ministerial Taskforce on Maternal Health in Papua New Guinea was launched in 2009 to establish a way forward to protect the future health of girls and women [22]. 
In January 2011, the PNG National Department of Health (NDoH), with technical advice from the PNG office of the World Health Organization (WHO) and support from the WHO Collaborating Centre at the University of Technology Sydney (WHO CC UTS) developed the Maternal and Child Health Initiative (MCHI). This was one of a number of key initiatives aimed at addressing the identified emergency in maternal and child health. The MCHI was funded by the Australian Government initially for two years (January 2012 - December 2013), with the long-term objective to contribute to decreasing maternal mortality rates in PNG through improved essential maternal and newborn care. The $\mathrm{MCHI}$ has subsequently been extended until the end of 2015. The $\mathrm{MCHI}$ is coordinated through Family Health and the Human Resources Departments in the NDoH.

The MCHI utilises a capacity building approach involving support, guidance, mentoring and continuing professional development. Eight international Clinical Midwifery Facilitators (CMFs) were placed in four midwifery training schools across the country to mentor Papua New Guinean midwifery educators. Two international obstetricians were placed in two regional hospitals that previously did not have ready access to an obstetrician. The role of these international midwives and obstetricians was to facilitate an improvement in clinical teaching and practice in addition to providing mentoring and supervision to midwifery educators, students and other clinicians. Midwifery educational resources including textbooks, teaching resources and mannequins were supplied to the four midwifery schools. Three training workshops were held each year for midwifery educators and clinicians to build confidence and competence in teaching, clinical practice skills and leadership. Weekly teleconferences were conducted with the CMFs and monthly communication occurred between the CMFs, obstetricians and the team at WHO Country office in Port Moresby. The 
Australian government also provided PNG midwifery student scholarships that included a stipend for the duration of the 12 month course that covered accommodation and living expenses.

All midwifery programs are guided by a standard midwifery curriculum and all schools have undertaken a process of accreditation of their program in line with the national standards. The National Midwifery Curriculum was developed in collaboration with WHO and NDoH and first taught in 2010 at the four training institutions in PNG. The course is only available to those who are registered nurses. The 12 month program is known as a Bachelor of Midwifery and includes supervised clinical practice and theoretical teaching in the midwifery school, as well as a rural placement.

The $\mathrm{MCHI}$ is directed through a Steering Committee meeting led by the $\mathrm{NDoH}$. This provides leadership, as well as being a forum for communication updates, information sharing and feedback to enhance all facets of the $\mathrm{MCHI}$.

A longitudinal evaluation research project was undertaken throughout the implementation of the first, two year phase of the MCHI 2012-2013. The aim of the evaluation was to monitor the progress of the initiative and identify lessons for scaling up midwifery that could be applicable to other low or middle-income countries (LMIC).

The longitudinal study sought to answer the following questions:

- What are the experiences of PNG midwifery students and midwifery educators?

- Has the supply of midwives increased?

- Has the quality of midwifery education increased? 
- Has midwifery clinical training capacity been strengthened through development of the faculty?

- What changes have there been at service delivery points?

- What changes have occurred in midwifery regulation?

The aim of this paper is to present the findings of the evaluation of the first two years of the $\mathrm{MCHI}$ and lessons learned that may be transferable to midwifery capacity building efforts in other settings.

\section{METHOD}

This descriptive study employed a mixed methods design involving concurrent collection of data from a variety of sources to provide multiple perspectives on the outcomes of interest. This approach acknowledges the multiple meanings and constructed realities of all participants and is based upon a pragmatist approach that enables the most relevant method to be selected in line with the stated evaluation objective and related questions. Multiple voices also provide a mechanism for all stakeholders to be engaged in the evaluation. Such an approach can foster ownership and ensures that programs and processes are culturally relevant and locally defined, therefore enhancing the likelihood of performance improvements [23].

The monitoring and evaluation framework that was developed for the $\mathrm{MCHI}$ was underpinned by a program logic model. This aimed to achieve nine short to medium term outcomes that could contribute to reaching long-term impacts. These were informed by interdependent components of systemic capacity building, as outlined by Potter et al. [12]. The program logic is summarised in Figure 1. In the monitoring and evaluation framework 
the input and outputs are organized under objectives, each with qualitative and quantitative measures or key verifiable indicators alongside the data required for verification and collection time periods. Ethical approval was provided by The Government of Papua New Guinea's Medical Research Advisory Committee (NDoH MRAC No. 11.36) and ratified by the Human Research Ethics Committee at the University of Technology Sydney.

The $\mathrm{MCHI}$ evaluation acknowledges that capacity building is both gradual and political [24]. Exact causal pathways are sometimes difficult to specify and outcomes are context dependant. The monitoring and evaluation framework therefore sought to chart the ripple effect of the $\mathrm{MCHI}$ initiative and understand 'what works for whom and under what conditions' [25]. These changes were captured through on-going data analysis that included an examination of the patterns emerging from individual accounts of changes, as well as those shared across participants with similar characteristics (for example, occupational group, place of employment, gender and location). This provides insight into expected as well as unexpected changes in how people work together effectively to achieve project goals.

Figure 1 Project Logic model developed for Phase 1 of the Maternal and Child Health Initiative

Data sources

Data were collected at multiple points over the two year period by researchers from Australia and by staff within the WHO country office in PNG. A number of data sources were used for the evaluation (Table 1). Focus group discussions (FGD) and semi structured interviews were selected to enable participants to contribute their learning and stories. The FGDs and interviews were facilitated in PNG by members of the research team. We asked 
clinicians to describe changes they had experienced with respect to a number of aspects of their working relationships including their own professional development, the education of midwifery students, the capacity of midwifery educators and graduates and issues with midwifery regulation. Students were asked to describe their learning in the midwifery program including aspects that they particularly enjoyed and challenges and ideas for improving their experience.

Surveys were used to gather information after workshops and to gain insight into the overall success or otherwise of the $\mathrm{MCHI}$, from various stakeholders. In addition, a Faculty Development Survey, developed by a global working group of the WHO Western Pacific Regional office and coordinated by the UTS WHO CC, was implemented in 2011 and 2012. The aim of this survey was to provide insight into nursing and midwifery teaching capacities and workforce development to help inform the development of education programs across PNG.

Table 1: Data collected for the MCHI Evaluation (2012-2013)

Participant selection and sampling

Purposive selection [26] of participants for the interviews and focus group discussions was employed with the aim of ensuring diversity in terms of their role, cadre and experience. We aimed to document a range of views on the $\mathrm{MCHI}$ to help identify any patterns. A list was developed of all possible participants per occupational group and a matrix was created to map various participant characteristics such as gender, age, position and institution across the groups. The matrix was used to select participants with a diversity of characteristics across each occupational group. These individuals were invited to participate via email, letter or phone messaging. Surveys were given to all workshop participants and sent to all 
relevant students, course co-ordinators and clinicians. Data were collected from multiple sites including, four midwifery schools, the hospitals where the midwifery schools had their clinical attachments, the hospitals where the obstetricians were located, various workshop locations and the NDoH in Port Moresby.

\section{Data analysis}

Qualitative data were analysed using a directed content analysis [27] in the first instance to identify the participants' accounts that related to the $\mathrm{MCHI}$ and other inputs and outputs and the effects of these, as summarized in Figure 1. Qualitative data analysis was undertaken using the software tool QSR NVivo 10. Regular meetings with the research project team were held to discuss the findings from the qualitative data and to identify patterns within and across all transcripts. Interviews and focus group discussion data continued until no new information could be gleaned from the transcripts, indicating data saturation. The qualitative findings were also discussed in the light of the survey results. These were analysed descriptively using Microsoft Excel 2010 software, as they became available from field staff in PNG.

Each data set was analysed separately and then integrated iteratively by drawing metainferences across all data using QSR NVivo 1. This involved the integration of the separate phases of quantitative and qualitative results (inferences) into coherent and meaningful 'meta-inferences [28] using a coding framework that was informed by Potter et al. four-tier hierarchy of capacity building elements [12]. The coding framework was used for data synthesis to identify achievements and progress with capacity building. This included elements that underpinned the monitoring and evaluation framework, including the program logic inputs, outputs and outcomes. This coding frame assisted in examining if, and 
how, the $\mathrm{MCHI}$ had contributed to building the capacity of structures, systems and roles that enabled the effective use of staff and infrastructure. In addition we were able to identify if this allowed educators and clinicians to apply their knowledge and skills that, in turn, enabled the effective use of tools and equipment. The integration phase aimed to identify patterns across all data to establish the extent and levels of capacity built during the $\mathrm{MCHI}$ project. This process allowed the data to be synthesised into a coherent whole which was achieved through negotiation within the research team and discussions with stakeholders at scheduled meetings.

\section{FINDINGS}

The findings from the qualitative and qualitative data analysis are reported according to the contribution that the $\mathrm{MCHI}$ has made to midwifery clinical teaching and practice and to obstetric care in the project sites as per the short to medium term outcomes.

\section{Increased learning opportunities for midwifery educators}

The PNG midwifery educators reported benefits from the role provided by the capacity building provided through the $\mathrm{MCHI}$, both in the clinical setting and in the teaching sites in the universities. The PNG midwifery educators described the enhanced learning opportunities that had resulted from the mentoring and support provided by the CMFs. One reported:

This year, I am becoming more confident with my counterpart around me. She is helping me in so many different ways in my skills, especially midwifery. Like some things I am used to doing but they say, oh this is not evidence based, and I go, OK, I have to change 
this practice. That's good - it's challenging. It took me lot of time to adjust to the CMFs (PNG midwifery educator FGD).

The midwifery course coordinators identified those areas where they felt the CMFs had contributed most to increasing their knowledge and skills. These were using different assessment strategies and tools; planning and organization; curriculum design and development; using different approaches to teaching and enhanced presentation techniques in the classroom. The skills that were less impacted on were: report writing; using the internet to search for information; using research; and getting evidence in practice.

The workshops were reported as being useful for building skills and strategies in teaching and learning, and for receiving updates on clinical topics. The workshops were seen as a valuable means to participate in continuing professional development (CPD), an opportunity that few midwives in PNG have ready access to. Barriers to taking up CPD were highlighted in the Faculty Development Survey where heads of schools and educators reported that high workload demands often made it difficult for staff to be released from teaching duties to attend educational events (Figure 2). Other barriers to professional development included a lack of awareness of events, events that were not relevant to practice and a lack of funding.

Fig. 2 Barriers to attending professional development opportunities

\section{Increased midwifery educators teaching capacity}

The PNG midwifery educators reported improved teaching capacity as a result of working alongside the CMFs. One PNG educator said "I have learnt a lot from the CMFs, like some of 
the teaching methodology. These are all new things which I was not exposed to previously" (PNG midwifery educator FGD). The educators had introduced a number of new teaching techniques such as the use of visual teaching aids, computer skills and the creation of worksheets for specific topics. Closer monitoring of students who were having difficulties was also described, including the regular review of students' progress using a skills logbook.

In-service education for clinical staff in the hospital was provided by the academic staff whilst students were on clinical placement. These sessions were said to have improved the students' academic results as well as professional relationships and communication between the hospital and the midwifery teaching team. CMFs noted that the educators had adopted "student centred approaches", and a "variety of teaching methods". Most importantly one CMF noted that educators:

... had a greater connection between the theory and clinical components of the course, and an increased presence of academic staff in the clinical setting supervising, mentoring and assessing student abilities than was previously seen (CMF FGD).

Despite these improvements, considerable resource challenges were outlined by the educators, which affected their ability to apply what they had learned, into their teaching practice. These challenges included lack of transport, insufficient learning materials, lack of teaching staff, overcrowded classrooms, a high staff-student ratio and limited access to rural and remote clinical placement sites.

Improved clinical education experiences for students 
The majority of midwifery students surveyed provided positive and consistent feedback regarding the knowledge, skills, attitudes and approaches to teaching as provided by their educators and CMFs in the classroom and in the clinical settings. Many also reported that undertaking theory as well as practical application was important for their learning:

Both theory and clinical because what we learnt during theory when we are not in clinical we implement the knowledge and skills which is good. When you learn something and put into practice, you will remember (Student survey).

PNG educators and the CMFs commented on an improved learning capacity from the students over the 2 years period of the MCHI. One CMF described the increased level of student confidence:

I notice that as time goes by the students are actually exercising their power a little bit more and saying no, I'm going to do it this way. This student was able to say what she had been taught and what she knew was right to do (CMF survey).

Clinical supervision to enhance learning was an important issue. Just over 50 per cent of students indicated that clinical supervision was adequate while other students highlighted that, due to a shortage of staff it was not always possible to receive supervision. In extreme cases, some students indicated that they had not received any supervision at all or only rarely received supervision in the clinical setting. Reasons for this situation, as described by students, included: educators were either too busy, or absent from the clinical areas; a lack of midwives on the wards to supervise student learning and; a lack of supervision due to large numbers of students from different disciplines each competing for clinical supervision from limited numbers of staff. 


\section{Increased quantity and quality of midwifery graduates}

The scholarships funded by the Australian Government were found to be important in increasing the number of midwifery graduates. There were 49 graduates in 2011, increasing to 76 in 2012 and 107 at the end of 2013. Each school has increased its uptake considerably. The attrition rate for 2013 was low, less than four per cent mainly due to sickness. Several students who had to leave due to illness or misadventure, re-enrolled in the following semester to complete their studies.

Table 2: Numbers of graduates and midwifery students lost to attrition across the 4 schools (2011-2013)

Feedback from midwifery educators and CMFs regarding the quality of graduates was encouraging, for example, one CMF and PNG Midwifery Educator reported:

The Initiative has made the most impact in the skills of the students. I believe that the recent graduates are more compassionate to the women. In addition they have increased their knowledge and skills in all areas of midwifery care. (CMF Survey 2013) I feel better about looking to the future. The students are an amazing source of great hope for me. I look at them and I see what they're learning. They're not all thinking at the same level but there's enough questioning and learning and moving forward with the students that makes me think that there is actually hope that at the end of this we are going to produce midwives who are going to be great midwives and great advocates for women (PNG Midwifery Educator FG 2012) 
One of the strengths of the CMF's input was to gently shift the philosophical underpinnings of midwifery into a more woman-centred respectful and compassionate model of care. Some graduating students spoke about how they have changed the way they speak to women in labour and "be there for the mother", "allow women to take different positions in labour" and "involve men as much as possible".

Many stakeholders, students and educators stated that the 12 month program was too short to ensure that graduates had the requite skills, especially to practise in rural and isolated areas. They felt that the course should be extended to at least 18 months in order to provide a more robust clinical experience for students. In addition, they felt that there needed to be a stricter selection criterion for students applying to study midwifery, as this would ensure a more able student and more competent graduate.

\section{Increased capacity of clinicians in participating sites}

The obstetricians reported significant improvements in the safety and quality of health care delivery as a result of the $\mathrm{MCHI}$. One clinician noted that there is "now a qualified midwife in every health centre who is able to manage complications that arise" and that clinical practice had improved due to increased number of clinical meetings and outreach programs. Clinicians also reported that educating midwives and nurses caring for women after miscarriages had resulted in a reduction of women presenting with sepsis and other complications resulting from unsafe village family planning practices.

Resource issues, including human, financial, equipment, medicines and infrastructure, were frequently cited as affecting graduates' ability to transfer their improved skills and knowledge into practice. Other constraints included a general lack of awareness about what 
"good quality health care" means in the PNG context and low staff motivation with " $a$ culture of no motivation, no incentives". Sustained staff training in infection control procedures and awareness and relationships building was said to have contributed to improved quality of maternal and newborn. Another clinician described "trying to motivate the people on the job, because when you have job satisfaction you are motivated" (MCHI obstetrician interview).

\section{Improved quality of the midwifery curricula}

Many new teaching strategies had been implemented since the commencement of the $\mathrm{MCHI}$ and these have enriched the quality of the curricula. For example:

They have helped in ideas during preparations of lessons to teach the students. We have done 'emergency obstetrics care' skills together as teaching and learning exercises. We have taught simulations on the 'dummies' as part of teaching students but also learning it ourselves (PNG Midwifery Educator)

\section{Progress towards regulation of midwifery}

Considerable work had been undertaken by the four schools towards gaining accreditation of the midwifery curricula by the PNG Nursing Council. Much of this work was supported through the MCHI. Additional technical support funded by Australian Aid was also provided to the Nursing Council. The midwifery curricula in all midwifery schools have now been formally accredited and midwifery graduates registered with the PNG Nursing Council, a process that had not occurred in the past five years. The length of the midwifery program is also currently under review by the schools and the PNG Nursing Council. In the survey, all course coordinators noted that lengthening the program would be the best way forward to 
improve the quality of the new graduates and they recommended taking action at national, provincial and university level to enact change.

Increased opportunities for key stakeholders and participating PNG clinicians to network and collaborate

The regular $\mathrm{MCHI}$ workshops provided an opportunity to collaborate and network especially with senior personnel from NDoH and WHO. Opportunities for networking enabled better communication with service providers in provincial health care facilities that have strengthened referral and in-service training.

Collaboration was found to be hampered in some instances at the start of the programme. Tensions were reported between the CMFs and the PNG midwifery educators being due to differences in social economic status, remuneration and working conditions. However, relationship building efforts including frequent team meetings, equal sharing of workload, team teaching, shared social activities and sharing visions and ideas were reported to have increased understanding, acceptance and respect. For example:

Some academic and clinical colleagues are reluctant to engage - I think relationship is the basis of capacity building, so will continue to work on developing these. Also I think our colleagues have seen a lot of programs, initiatives come and go so there may be some reticence on their part to engage yet again. I think the fact we have been here for 2 years and the program is set to continue for another 2 years will help to establish these more difficult relationships, and gain acceptance for the CMFs and national colleagues. (CMF Survey 2013) 
The PNG staff also commented on collaborative practice that resulted from working with the CMFs:

We have a very good working relationship. There is consultation and you know, working with our curriculum and all those things. It's clear we all work together as a team and I think the workload is good because we share the workload and especially with our CMFs. They are really so much help and assistance (PNG Midwifery educator)

Communication issues due to problems with phone lines and intermittent internet services were common and made networking between workshops challenging.

\section{Ongoing supportive environment for $\mathrm{CMFs}$ and $\mathrm{MCHI}$ obstetricians}

The interviews, FGD's and surveys revealed the importance of weekly teleconferences with the CMFs and obstetricians to build and maintain an on-going supportive environment. One CMF said:

The teleconference allows CMFs to connect, debrief and share information and ideas in a confidential environment. The teleconference currently also includes the course co-ordinators on a monthly basis and provides a valuable forum for them to also connect and share ideas. The inclusion of the obstetricians at times (although not often enough) has provided an opportunity for clinical debate and discussion and sharing which has been useful. In terms of on-going professional development and clinical mentoring for the CMFs, I feel the teleconference fulfils an essential role. (CMF Survey 2013) 
The workshop evaluations indicate that participants regarded these sessions as being helpful in supporting the ongoing capacity budiling work. One participant stated that the workshop was "very important to strengthening connectedness and communication between each group sharing" ( $\mathrm{MCHI}$ workshop evaluation). Program logistics, medical and security support was generally positively received by $\mathrm{CMFs}$ and $\mathrm{MCHI}$ obstetricians in the interviews, although communication issues between the various partners were noted.

\section{DISCUSSION}

The findings from the analysis of data gathered over the two years of the implementation of the $\mathrm{MCHI}$ show that the initiative has made a significant contribution to strengthening the midwifery workforce in PNG. Achievements include the provision of increased learning opportunities for midwifery educators, improvements in midwifery educators teaching capacity and enhanced clinical education experience for students. Progress has also been made in terms of increasing the quality of midwifery graduates, as well as administrative and legal preparations towards the accreditation of midwifery programs and the regulation of graduates. The technical capacity of midwifery and obstetric clinicians reportedly had increased and improvements were noted in the supportiveness of the environment for clinical staff.

Clinical preceptor-ship to support clinical learning still requires more intensive support to build capacity, both of students and staff. Increased opportunities for key stakeholders and participating PNG clinicians to collaborate and strengthen skills were also outlined by respondents and international staff also reported being supported to deliver the program. 
There are a number of key issues for consideration in terms of midwifery capacity building in PNG and potentially in other low and lower-middle income countries. These issues include the possible extension of the midwifery curriculum from 12 to 18 months to bring it in line with the International Confederation of Midwives Global Standards of Midwifery Education [29] and the critical support required to progress efforts to accredit midwifery curricula and regulate new graduates. Experiences from Africa and Afghanistan may provide insights for sustaining the support the process of midwifery regulation in PNG. The regional African Health Profession Regulatory Collaborative (ARC) for Nurses and Midwives has adopted an approach to strengthening nursing and midwifery regulation through collaborative improvement cycles. This involves regional meetings of nursing and midwifery leaders, the awarding of grants to support national regulation improvement projects, and the provision of technical assistance to country teams to address identified regulatory issues [30]. The work has also been successful in engaging leaders in regulatory reform [31] and led to the development of a framework for measuring regulatory strengthening [32]. Afghanistan's experience towards the provision of quality midwifery education may also provide lessons applicable to the PNG context. A national mechanism was developed to accredit midwifery schools that was underpinned by policy and involved the development of educational standards and tools to assess the achievement of these; technical support to identify issues and solve problems; and a system of official recognition [33].

The $\mathrm{MCHI}$ evaluation also identified challenges in relation to building a supportive midwifery working environment in health and training facilities. These included a lack of supervision for students primarily related to resource issues, communication issues between partners and low staff motivation. Other research examining the working environment of health 
workers in PNG may provide further insight into factors affecting staff motivation and job satisfaction that the $\mathrm{MCHI}$ may need to consider. Jayasuriya and colleagues found that interpersonal relationships, the work climate and supportive supervision are the most important influences of job satisfaction for rural nurses [34]. A qualitative study by Razee et al. noted the strong influence of community support in motivating health workers [35].

Leadership from midwives, along with expertise and collaboration are central aspects of the provision of quality maternal and newborn care [36-38]. Despite leadership being a component of the $\mathrm{MCHI}$ training workshops and some participants being provided additional opportunities to attend leadership training in other countries, this was not emphasised by the participants as an area of note in the evaluation. This may be because the MCHI was still only in its early stages and PNG midwives have not as yet had the opportunity to apply related knowledge and skills. Despite this, PNG midwives showed leadership in their teaching and presentations at international conferences. International mentoring may prove useful in the next stage of the $\mathrm{MCHI}$ and may include building midwifery research leadership for the future [39].

The second phase of the $\mathrm{MCHI}$ is now underway and data are being collected to assess the success of modifications made to the program to address lessons learned in the initial phase and evaluate the consolidation and scaling up of achievements. However, the greatest challenge will be to ensure mechanisms are left behind, in country, to sustain the initiative. Insights into the factors that may help to sustain the $\mathrm{MCHI}$ activities and benefits over time is provided by Schell and colleagues who have presented a framework for public health sustainability [40]. This involves a framework that includes high-level political commitment, strategic planning, program adaptation and public health impacts. This framework could be 
used in the $\mathrm{MCHI}$ to gain an understanding of current efforts and gaps across each domain and to plan future strategies and ensure all opportunities for embedding the program have been harnessed.

Sustainability on the investment and gains made after the $\mathrm{MCHI}$ finishes is critical. This evaluation has reported the experience across the whole sector but there have been some schools and health services that have been more successful than others in capacity building. It is evident that while this approach to capacity building is effective, individuals need to be in place and ready to be 'capacity-built'. Further research to explore the barriers to capacity building in different contexts is necessary to build further on the successes and ensure longterm sustainability.

\section{Study limitations}

This study has been affected by numerous factors that have influenced the data collection, analysis and interpretation. Gathering data in PNG is challenging due to geographical, logistical and political issues. The sites were located in diverse geographical areas requiring difficult road travel and expensive air flights. The consistent collection of audit data was an on-going challenge. The complex partnership structure of $\mathrm{MCHI}$ meant that partners had different views about what data should be collected and how. These philosophical differences and cross-cultural challenges may have affected the quality of data collected and the findings. The UTS evaluation team regularly presented partners and stakeholders with the evaluation results throughout the two years at meetings and training workshops providing stakeholders with the opportunity to add to or modify emergent findings. Useful feedback was provided on these occasions and this was incorporated into the evaluation. In addition the limited available baseline data made it difficult to show the extent of progress 
that can be attributed specifically to the $\mathrm{MCHI}$ in all areas. The challenges of evaluating capacity building are well described in the literature [16]. However we believe this evaluation benefited from a clear and realistic monitoring and evaluation framework that was developed at the onset of the initiative and a useful blend of quantitative and qualitative tools that helped to provide a broad picture of positive change.

\section{CONCLUSION}

This paper suggests that the $\mathrm{MCHI}$ has contributed to key areas of midwifery capacity building including improving education and training, engaging nurses and midwives in decision making, enhancing workplace environments, building leadership and global collaboration. The Australian Government is supporting a second, two year phase of this initiative which is currently underway, providing an important opportunity to consolidate these achievements and work towards integrating strategies to strengthen midwifery in PNG into local, provincial and national structures and systems in a sustainable manner.

\section{ACKNOWLEDGMENTS AND DISCLOSURES}

Thank you to all the midwifery and medical clinicians, educators, CMFs, MCHI obstetricians, students, policy makers, regulators, funders and other stakeholders who have been involved in the $\mathrm{MCHI}$ over 4 years and for their commitment and contribution to this evaluation. The authors would also like to acknowledge funding from the Australian Government Department of Foreign Affairs and Trade that supported this study. The authors do not declare any conflicts of interest. 


\section{REFERENCES}

1. WHO. Nursing And Midwifery Capacity To Contribute To Health System Strengthening And The Achievement Of MDGS 13th Meeting Of The Global Advisory Group For Nursing And Midwifery Development (GAGNM) - Meeting Report. Geneva: World Health Organization, 2010.

2. WHO. Strategic Directions for Strengthening Nursing and Midwifery Services 2011-2015 Geneva: World Health Organization, 2010.

3. WHO. WHO Consultation on the Transformative Scale-Up Of Medical, Nursing and Midwifery Education Second Technical Reference Group Meeting: Nursing And Midwifery Education Experts Geneva: World Health Organization, 2010 15-16 July

4. Brechin S, Sacknoff D, Curran K, Asport S, Vargas M. Evaluation of the Institutionalization of Family Planning/Reproductive Health Inservice Training in Bolivia. Baltimore: JHPIEGO Corporation and United States Agency for International Development, 2003.

5. Mogobe K, Bruce J, Meyer S. Collaboration in higher education for nursing and midwifery in Africa (CHENMA). Africa Journal of Nursing and Midwifery. 2009; 11(1):5-15.

6. WHO. Health service planning and policy-making: a toolkit for nurses and midwives. Manilla: World Health Organization, 2005.

7. Buchan J. HRH Issues and the Minimum Dataset Sydney: University of Technology, 2006.

8. SANNAM. South Africa: Southern African Network of Nurses and Midwives; 2011 [cited 2014 28 August]. Available from: http://www.sannam.org.za/projects.html.

9. WPRO. South Pacific Chief Nursing and Midwifery Officers Alliance (SPCNMOA) Manilla: World Health Organization Western Pacific Regional Office; 2013 [cited 201428 August]. Available from: http://www.wpro.who.int/hrh/documents/spcnmoa/en/.

10. Wright S, Cloonan P, Leonhardy K, Wright G. An international programme in nursing and midwifery: building capacity for the new millennium. International Nursing Review. 2005; 52(1):1823. doi: 10.1111/j.1466-7657.2004.00250.x.

11. Dawson A, Brodie P, Copeland F, Rumsey M, Homer C. Collaborative Approaches Towards Building Midwifery Capacity in Low Income Countries: A Review of Experiences Midwifery. 2013. doi: doi.org/10.1016/j.midw.2013.05.009.

12. Potter C, Brough R. Systemic capacity building: a hierarchy of needs. Health Policy and Planning. 2004; 19(5):336-45. doi: 10.1093/heapol/czh038.

13. Van Lerberghe W, Matthews Z, Achadi E, Ancona C, Campbell J, Channon A, et al. Country experience with strengthening of health systems and deployment of midwives in countries with high maternal mortality. The Lancet. 2014.

14. Hawe P, King L, Noort M, Jordens C, Lloyd B. Indicators to help with capacity building in health promotion. Australian Centre for Health Promotion, 2000.

15. Crisp BR, Swerissen H, Duckett SJ. Four approaches to capacity building in health: consequences for measurement and accountability. Health Promotion International. 2000; 15(2):99107. doi: 10.1093/heapro/15.2.99.

16. Simister N, Smith R. Monitoring and Evaluating Capacity Building: Is it really that difficult? INTRAC, 2010.

17. UNDP. Human Development Report 2014 Sustaining Human Progress: Reducing Vulnerabilities and Building Resilience. New York: United Nations Development Programme, 2014. 18. PNG National Statistics Office. Demographic Health Survey of Papua New Guinea 2006. Port Moresby: Government of Papua New Guinea, 2009

19. NSO. Papua New Guinea National Household Income and Expenditure Survey 2009-2010. Port Morsby: National Statistical Office - Government of Papua New Guinea 2012.

20. Bank W. PNG Country partnership strategy 2013-2016. Washington DC World Bank, 2012. 21. UNFPA. The State of the World's Midwifery Report. New York: United Nations Population Fund; 2014. 
22. National Department of Health. Ministerial Taskforce on Maternal Health in Papua New Guinea. Port Moresby: Government of Papua New Guinea; 2009.

23. Baser H, Morgan P. Capacity, Change and Performance. Maastricht, Netherlands: European Centre for Development Policy Management, 2008.

24. James R. Practical Guidelines For The Monitoring And Evaluation Of Capacity building: Experiences From Africa. Oxford, UK: The International NGO Training and Research Centre, 2001. 25. Prashanth NS, Marchal B, Hoeree T, Devadasan N, Macq J, Kegels G, et al. How does capacity building of health managers work? A realist evaluation study protocol. BMJ Open. 2012; 2(2). doi: 10.1136/bmjopen-2012-000882.

26. Trost JE. Statistically non-representative stratified sampling: a sampling technique for qualitative studies. Qualitative Sociology. 1986; 9(1):54-7.

27. Hsieh H-F, Shannon SE. Three approaches to qualitative content analysis. Qualitative health research. 2005; 15(9):1277-88.

28. Onwuegbuzie AJ, Combs JP. Emergent Data Analysis Techniques in Mixed Methods. In: Tashakkori A, Teddlie C, editors. SAGE Handbook of Mixed Methods in Social \& Behavioural Research. Thousand Oaks: Sage; 2010. p. 397-430.

29. ICM. The ICM Global Standards for Midwifery Education. The Hauge: International Confederation of Midwives, 2014.

30. Gross J, McCarthy C, Kelley M. Strengthening nursing and midwifery regulations and standards in Africa. African Journal of Midwifery and Women's Health. 2011; 5(4):185-8. doi: 10.12968/ajmw.2011.5.4.185.

31. McCarthy CF, Voss J, Salmon ME, Gross JM, Kelley MA, Riley PL. Nursing and midwifery regulatory reform in east, central, and southern Africa: a survey of key stakeholders. Hum Resour Health. 2013; 11(1):29.

32. McCarthy CF, Kelley MA, Verani AR, Louis MES, Riley PL. Development of a framework to measure health profession regulation strengthening. Evaluation and program planning. 2014; 46:1724.

33. Smith JM, Currie S, Azfar P, Rahmanzai AJ. Establishment of an accreditation system for midwifery education in Afghanistan: maintaining quality during national expansion. Public health. 2008; 122(6):558-67.

34. Jayasuriya R, Whittaker M, Halim G, Matineau T. Rural health workers and their work environment: the role of inter-personal factors on job satisfaction of nurses in rural Papua New Guinea. BMC health services research. 2012; 12(1):156.

35. Razee H, Whittaker M, Jayasuriya R, Yap L, Brentnall L. Listening to the rural health workers in Papua New Guinea-The social factors that influence their motivation to work. Social science \& medicine. 2012; 75(5):828-35.

36. Downe S, Byrom S, Simpson L. Essential Midwifery Practice: Expertise Leadership and Collaborative Working Chichester, West Sussex, UK: Wiley- Blackwell 2011.

37. Renfrew M, McFadden A, Bastos H, Campbell J, Channon A, Cheung N, et al. Midwifery and quality care: findings from a new evidenceinformed framework for maternal and newborn care. The Lancet. 2014; 384:1129-45.

38. UNFPA, ICM, WHO. State of the World's Midwifery. Barcelona: UNFPA, ICM and WHO; 2014.

39. Etowa J. Building Nurses' Leadership and Research Capacity Through International Mentoring. 41st Biennial Convention,; October 29-November 2; Grapevine, Texas, USA: Sigma Theta Tau International Honor Society of Nursing; 2011.

40. Schell SF, Luke DA, Schooley MW, Elliott MB, Herbers SH, Mueller NB, et al. Public health program capacity for sustainability: a new framework. Implement Sci. 2013; 8(1):15. 